The World of Plymouth Plantation 



\section{THE WORLD OF PLYMOUTH PLANTATION}

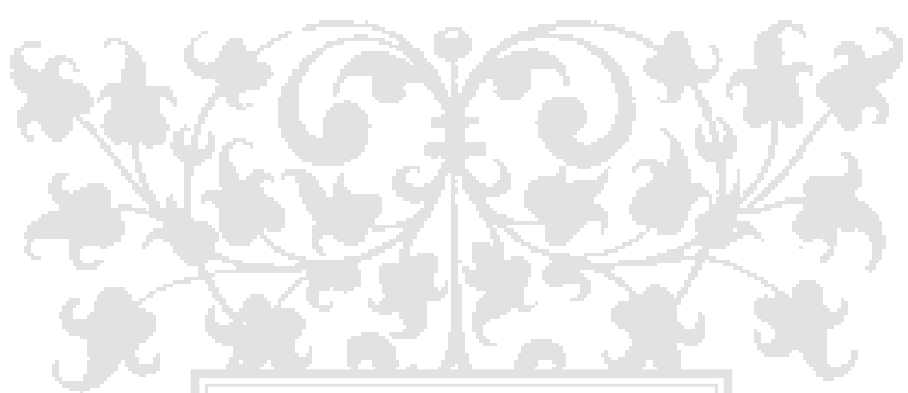

Carla Gardina Pestana

THE BELKNAP PRESS OF

HARVARD UNIVERSITY PRESS

CAMBRIDGE, MASSACHUSETTS

LONDON, ENGLAND

2020 
Copyright (C) 2020 by the President and Fellows of Harvard College All rights reserved Printed in the United States of America

First printing

Cover design: Sam Potts

$$
\begin{gathered}
9780674250802(\mathrm{EPUB}) \\
9780674250819(\mathrm{MOBI}) \\
9780674250826(\mathrm{PDF})
\end{gathered}
$$

Maps copyright (C) 2020 by Carla Gardina Pestana

The Library of Congress has cataloged the printed edition as follows:

Names: Pestana, Carla Gardina, author.

Title: The world of Plymouth Plantation / Carla Gardina Pestana. Description: Cambridge, Massachusetts : The Belknap Press of Harvard University Press, 2020. | Includes bibliographical references and index.

Identifiers: LCCN 2020003452 | ISBN 97806742385 Io (cloth)

Subjects: LCSH: Pilgrims (New Plymouth Colony) | MassachusettsHistory-New Plymouth, I620-I69I. | Massachusetts-Social life and customsTo I775. Massachusetts-Relations.

Classification: LCC F68 .P395 2020 | DDC 974.4/02-dc23

LC record available at https://lccn.loc.gov/2020003452 
To my history teachers, beginning with Ruby Marquis at Ranchito Elementary and culminating in Gary Nash and Joyce Appleby at UCLA. 
